\title{
Relationship Guidance Sources, Fears and Reasons for Marriage among Young Urban Christians in Kenya
}

\author{
Dinah W. Tumuti ${ }^{1,4, *}$, Anthony M. Ire ri $^{2}$, Jos hua W. Tumuti ${ }^{3}$ \\ ${ }^{1}$ Department of Design \& Marketing, Keny atta University, P.O. Box 43844, 00100, Nairobi, Kenya \\ ${ }^{2}$ Department of Educational Psy chology, Keny atta University, P.O. Box 43844, 00100,Nairobi, Keny a \\ ${ }^{3}$ Department of Business Administration, Keny atta University, P.O. Box 43844, 00100,Nairobi, Keny a \\ ${ }^{4}$ Directorate of Community Outreach and Extension Programmes, Keny atta University, P.O. Box 43844, 00100,Nairobi, Kenya
}

\begin{abstract}
Existing professional services for young people especially in developing countries need to be informed by the local situation for them to be effective. The study aimed at identifying sources of relationship guidance, young people's fea is and reasons for marriage. 65 young Christians in Nairobi with an average age of 25.23 (sd.4.38) completed a self-report questionnaire. Results indicate that the participants relied mainly on friends for relationship guidance. Social emotional benefits, especially companionship, were the major motivation for young people to marry. Infidelity and divorce were the main sources of fear of marriage. Suggestions for research and practice are given.
\end{abstract}

Keywords Relationship Guidance, Fears and Reasons for Marriage, Young Urban Christians

\section{Introduction}

Young adulthood presents marriage as one of its developmental tasks [1]. According to Erikson,[2], the major task facing young adults is dealing with the psychosocial conflict of intimacy versus isolation. Researchers posit that people resolve these identity issues by marry ing and rearing children,[3] or by entering into relationships that allow them to develop identities based on caring for others, [4]. Young people also have the developmental need for relatedness. To many young people, relationships with peers are a major source of emotional support and therefore enhance their psychological wellbeing,[6-7]. Falling in love, maintaining intimate relationships and marriage are some of the goals young people accomplish in their interactions with others [7].

The meaning attached to marriage is influenced by different factors. Further, the reasons why people fall in love and marry vary across cultures. Regarding marriage, researchers [7-8] distinguish between two categories of young people depending on what they think marriage to be: Marriage planners and marriage drifters. The marriage planners are inclined to regard marriage as adevelopmental process which progresses over time and is tested by real-life circumstances. Marriage drifters think of marriage as inevitable and a natural outcome of an early and untested relationship. While, the drifters are inclined to regard marriage as a promise of future commitment, the planners

* Corresponding author:

director-coep@ku.ac.ke (Dinah W.Tumuti)

Published online at http://journal.sapub.org/ijpt

Copyright (C) 2012 Scientific \& Academic Publishing. All Rights Reserved see marriage as the celebration of a commitment that is already established and time tested[8].

Family scholars have identified a number of conditions that have reshaped young people's notions of marriage. Some of the significant influences affecting the timing and attractiveness of marriage include: the extension of schooling beyond the teen years, the liberalization of sexual behavior, the availability of reliable methods of contraception, changing gender roles, the threat of divorce, and acceptability of remaining single [7]. Interestingly, despite the changing attitudes towards the institution of marriage a mong different societies, the proportion of young people opting for marriage is not different from it was at the beginning of the last century [8].

A common interest for caregivers, therapists and other practitioners working with young people is to help young people develop more healthy relationships and to function adaptively in their relationships [9]. However, rising divorce rates, increased levels of cohabitation, the advent of gay marriage, nonmarital childbearing, and relatively fe wer adult years spent in marriage have been cited as evidence of the steady and seemingly inexorable decline of marriage as a social institution $[7,10]$.

Another source of worry is that even where young people have been found to be appreciative of sexual relationships, they are non-commital about transiting these relationships into marriage[7,9]. In addition, young people's attitudes towards marriage are also swayed by media reports highlighting the dark side of love and marriage (e.g., high divorce rates, infidelity, stalking, domestic violence, etc.). The assumption that time kills romantic love may further undermine young people's decisions to enter into 
marriages [11]. Encouragingly, several researchers argue that marriage is not disappearing, but being transformed by the different contemporary conditions throughout the world[12-13]. In addition, the ideal and practice of matrimony are still valued by many[15].

There is, therefore, a need to find out factors influencing the lack of transition in the relationship cycle so as to inform therapeutic services aimed at helping young people prepare for and cope with marriage. In this article we briefly review relevant theoretical perspectives, previous research and report a study conducted among urban Christians in Nairobi on their sources of relationship guidance, fears about marriage and reasons why they would marry.

\subsection{Theoretical Perspectives}

Different theories have been advanced to explain love and attraction, sexual behaviour and mate selection. The different theories reveal that biological, cultural and economic factors are involved in human partner choice.

Pioneer research on love identified two major types of love: passionate and companionate. Passionate love includes an obsessive element, characterized by intrusive thinking, uncertainty, and mood swings. Companionate love, less intense than passionate love, combines attachment, commitment, and intimacy. It refers to deep friendship, easy companionship, the sharing of common interests and activities, but not necessarily including sexual desire or attraction[15]. Researchers argue that over time there is a linear passage of passionate love into companionate love[11].

As an effort to understand love, researchers have isolated its essential components. The triangular theory looks at love as comprising of three components: passion, intimacy, and commitment[16]. Passion is an intense physiological desire for someone; intimacy is the feeling that one can share all one's thoughts and actions with another; and commitment is the willingness to stay with another person through good and bad times. Ideally, a true love relationship comprises of all the three components and they jointly contribute to happiness in marriage[5]. Further, it is the different combinations of these components that result in different types of love. Passionate love is derived from a combination of intimacy and passion, without commitment; infatuated love, from passion without commitment or intimacy; and fatuous love, from passion and commitment, without intimacy. The theory argues that over the course of successful relationships the balance among these components often passes as time passes[5]. As passion generally decreases, both latent intimacy and commitment are said to increase[11].

Theories of attraction also highlight how personal factors like knowledge, attitudes, goals, power, shared circumstances and personality determine the individual's disposition towards getting attracted to a partner[1, 17]. The theory of assortative mating explains how people fall in love by stating that people find partners based on their similarity with each other. This assortative mating occurs along many dimensions including religious beliefs, physical traits, age, socioeconomic status, intelligence and political ideology among others [18]. According to the social-exchange theory, in personal relationships, including mate selection, individuals attempt to make rational choices. These choices are informed by the rewards and costs of their relationship status[19]. The theory proposes that people appraise their relationships based on the cost-reward spectrum. Thus everyone tries to maximize the rewards they obtain from a relationship and try to minimize the costs. If a relationship is to be successful then both parties are expected to give and take in equal proportions. When the costs outweigh the rewards, then the relationship is shunned.

According to the reinforcement-affect model we find some people attractive because they supply us with rewards, praise or benefits- which makes us associate them with pleasurable emotional experiences including among others praise, liking, and loving[20]. Thus when we stop associating them with any pleasurable experiences, our attraction to them fades. Similarly, the equity theory emphasizes upon the notions of fairness and equity. Individuals expect to receive rewards proportional to what they put in. If the relationship reaches an imbalance, then individuals appear dissatisfied and guilty. Studies involving newlyweds reveal that those who perceived themselves as having either over benefited or received low relationship benefits experienced dissatisfaction and guilt; but those experiencing equitable benefits had highest levels of satisfaction[20-22]. Coupled with other factors, low exchange can also lead to high marriage satisfaction. Thus a fundamental supposition is that individuals are self seeking in their relationships but this differs with cultures [5, 11].

The attraction-similarity hypothesis predicts that in ongoing relationships projection of the self onto the other person is the result of the attraction between the two individuals. It is said that in relationships attraction leads to perceptions of similarity [11].

Sociobiological theory emphasizes that individuals who have adaptive behaviours would live long enough to pass on those traits to their offsprings [11, 23]. Adaptive traits are those that promote survival of the individual and usually results in successful reproduction, therefore their genes will not die out. Thus according to this theory finding a mating partner is basically motivated by propagating one's lineage. Under this theory, the concept of Kin Selection is used to explain why we invest so much effort in taking care of our young and close relatives.

Biological theories emphasize that biological variables indirectly induce physiological, psychological, and social events which interact with the cultural context and leads to sexual prefe rences [5]. Other evolutionary work suggests that distinct systems evolved for mating, ro mantic attraction, and long-term attachments[21]; that in general, romantic attraction fades, but it may exist in long-term marriages serving to keep older couples energetic, optimistic, and with a companion[22-23]. 


\subsection{Literature Review}

Relevant literature has highlighted important changes that reflect a shift in the meaning and function of marriage[7]. For example, today's young people have a greater discretion about whether or not to marry. There has also been a shift in early entry into marriage over time. For example, current demographic data in Kenya indicate gender and regional differences in the age at first marriage. Half of all women enter marriage before their 20th birthday. Among women aged $25-49$, the median age at first marriage is 20 years which is a slight increase when compared with the median of 19.7 years in 2003. On the other hand, about 10 percent of men marry before their 20th birthday, and nearly half marry before age 25 . The median age at marriage a mong men aged 30 and above is 25.1 years and is unchanged since 2003 (it is is almost constant across the age cohorts, reflect ing stability over time) [24].

In Kenya, urban women tend to marry almost three years later than their rural counterparts. The difference by province of residence is more pronounced. Women from North Eastern, Nyanza, Western, Coast and Rift Valley provinces generally enter into marriage earlier than wo men in Nairobi, Central, and Eastern provinces. The difference in median age at marriage between North Eastern and Nairobi provinces is more than six years (17.9 and 24.2 respectively). The pattern of provincial differences has re mained similar to that of 2003, although the median age for wo men has increased slightly in most provinces. Median age at first marriage increases steadily as education level and wealth quartile increases [24]. Several studies shed light on these changes.

Worthman and Writing[25] studied social change in adolescent sexual behaviour, mate selection and premarital pregnancy rates among the Kikuyu community in Kenya. They reported a variety of social changes to have occurred in the community over the last eight decades. Schools have replaced the age set systemas the institutional fra mework for mate selection by providing social contact and defining marriageability by quantifying performance and qualifications as well as structuring access to socio-economic opportunities. Responsibility for mate selection remains with young people, but the determinants of partner desirability have shifted considerably. The traditional criteria for partner desirability included males ability to pay bride wealth and provide wife with land. For females, diligence and demeanour were the desirable traits. Presently, education and wage earning capacity affect partner attractiveness for each sex, creating quantitative and qualitative bases for differential desirability.

Another study assessed preferred occupations in mate selection among undergraduate students of two Kenyan universities[26]. The study involved 403 undergraduate students in different programmes. Findings indicate that students had preferred occupations in mate selection. The preferred occupations include computer science, pharmacy, medicine, banking and finance. Rejected occupations include: police, military, carpentry and fishing. Gender and one's course of study were the only variables that showed some influence on the way students made their preferences. Male students preferred occupations due to their being favourable while female students preferred those occupations that pay well.

In a study that assessed mate selection preferences of heterosexual college students from the evolutionary psychology perspective, it was established that the hypothetical partner's physical attractiveness and chastity were important to both men and women[27]. Another study investigated the extent to which Afro-Americans mate selection are consistent with those reported for other racialor ethnic groups. It established that gender was the strongest correlate and predictor of various mate selection preferences followed by age. The findings further indicated that men chose mates based on physical characteristics while women chose mates based on economic considerations [28]. This corroborated earlier findings by Buss [29] where men in different cultures felt attracted to women with physical features such as youthful face and forms while women felt attracted to men whose wealth, power and ambition promised resources for protecting as well as nurturing of offs pring.

Another study tested the attraction-similarity hypothesis in same-sex friendships by correlating individuals' satisfaction with an ongoing friendship with perceptions of similarity on traits and behaviors [30]. In addition, satisfaction in an ongoing friendship was manipulated and then perceptions of similarity were tested for. Consistent with the attraction-similarity hypothesis, the more satisfied individuals were with their friendships the more similar they perceived their friends to be to themselves. These perceptions of similarity were not predicted by the duration or closeness of the friendship. Finally, perceptions of similarity were made in a self-serving fashion.

Young people's attitudes towards marriage can also be swayed by media reports highlighting the dark side of love and marriage (e.g., high divorce rates, infidelity, stalking, domestic violence, etc.)[11]. Further, the assumption that time kills romantic love may also undermine people's decisions even to enter into marriages $[5,9,11]$.

Studies done with urban Kenyan youth also reveal changes and fears that young people have regarding marriage. In one study, 37 percent of $g$ irls reported that they worried that their husbands would give them HIV[31]. Most marriages were chosen and not arranged; parents were involved in only 11 percent of girls' marriages. Eighty-five percent of girls knew their spouse before marriage and 94 percent consented to the marriage. Over 60 percent considered that the timing of their marriage was too early; however, among these, 61 percent wanted to get married at the time, probably reflecting that their perceived mistiming of marriage was in hindsight[31].

Infidelity and domestic violence have also been reported among the married urban young people. For example, in the study by Population Council[31], ten percent of married girls admitted they had not always been faithful to their spouses. 
When asked about their husband's infidelity, many girls were not sure if their husband had always been faithful. Nine percent reported that their husbands had definitely not been faithful, while 23 percent were not sure, likely reflecting girls' suspicion of infidelity. Despite high rates of infidelity, real or suspected, few girls were able to insist on condom us e; only 37 percent of married girls were able to use a condom with their husbands when they wanted. High rates of domestic violence were also reported with one in six married girls having have been hit or beaten in the past three months. When asked the reasons for the beating, most married girls said that they had talked rudely to their husbands or disobeyed them, and many described instances where children were crying, food or clothes were spoilt, or domestic work not done. Some described finding their husband with another woman or husbands coming home drunk. These findings indicate that early marriages impact on young people's health, education and psychosocial wellbeing.

The study by Population Council also found that both married and unmarried young people had different views about marital relationships. On the vast majority of areas, girls held more liberal views toward marital relationships than did boys. Two thirds of boys felt that wives should defer to the man's opinion in case of disagreements; 58 percent of boys felt that it is a man's right to refuse to let his wife see her friends. Half of the boys and 29 percent of the girls felt that a girl is more protected from HIV once she gets married. Thus, girls are likely to find themselves in a position of powerlessness within the household of their husband's family, with no clear access to friends of the same age or other sources of support. This powerlessness means they are more vulnerable to abuse and may also have to bear an excessive burden of domestic work. This in itself may be a source of fear for the unmarried.

A study among adolescents in seven churches in Nairobi revealed that they were having unresolved problems and concerns in areas such as boy/girl relationships, drug abuse and anxiety about bodily changes. However, the methods used by the pastoral workers in giving guidance in the seven churches, did not effectively help resolve adolescents' problems[32]. There is therefore, a need to inform pastoral programmes on some of the issues affecting young people regarding their relationships.

It is evident from the above review that, tradition, relig ion and education dictate the timing of marriage among young people in Kenya. However, few studies have studied the sources of relationship guidance among young Christians in urban areas. The reality is that the transition to marriage is a time when young people, especially girls are likely to be extremely vulnerable and in need of considerable support. Rates of HIV infection among adolescents in sub-Saharan Africa underscore this vulnerability [33]. There is, therefore, need to carry out research focusing on neglected sections of young people so as to inform programmes that target their wellbeing.

Against this background, the current study sought to achieve the follo wing objectives:

1. To find out whether young urban Christians are interested in marriage.

2. To investigate the reasons why young urban Christians would engage in marriage.

3. To find out the fears that the young urban Christians have about marriage.

4. To establish the sources of relationship guidance among the young urban Christians

5. To suggest interventions to address the fears that young urban Christians have about marriage.

\section{Methodology}

\subsection{Participants}

The average age of the participants involved in this study was 25.23 years (sd.4.38). All the participants involved in the study were single and born again members of the Presbyterian Church of East Africa- Nairobi North Presbytery. Table 1, summarizes the socio-demographic characteristics of the participants.

\subsection{Instruments.}

Data collection was through a questionnaire comprising of self-report items designed by the researchers. The questionn aire had different sections which collected information regarding: de mographics; participants' preferred sources of relationship guidance, fears about marriage, and other qualitative details not addressed in this paper. The psychometric properties of the questionnaire were established through a pilot study whose results informed the refining of the instrument by: ascertaining the type of data expected and familiarizing the researcher with the administration and coding procedures. Items that appeared vague were either revised or dropped altogether. The researchers consulted two youth counsellors to enrich the validity of the questionnaires. Participants were given 30 minutes to fill the questionnaire in their respective churches. After collection, the researcher clarified any fears that the participants had about the data. The filled questionnaires were coded by the researchers and then analyzed using SPSS.

\subsection{Ethical Considerations}

The researchers duly informed the participants of the purpose of the study and any possible risks of involve ment in it. The participants' consent was sought and they were informed of their freedo $m$ to withdraw from the study at any point if they found their security to be compromised. To ensure that the identity of the participants remained anonymous, random codes were used for the questionnaires. The researchers also got clearance from the relevant authorities in Kenya before embarking on the data collection phase of the study.

\section{Results}


This section presents results on the sociodemographic characteristics of the participants, their expectations on whether their current relationships would end in marriage, reasons why they would consider marrying in future, the people young people turned to for their re lationship guidance and their fears regarding marriage.

Table 1. Sociodemographic charact eristics of the participants

\begin{tabular}{|c|c|c|}
\hline Variable & Frequency $(\mathrm{N}=65)$ & Percentage (\%) \\
\hline Gender & 34 & 52.3 \\
Male & 31 & 47.7 \\
Female & 39 & \\
\hline Age (Mean=25.23) & 24 & 60.0 \\
$\leq 25$ & 1 & 36.9 \\
$26-30$ & 1 & 1.5 \\
$31-34$ & & 1.5 \\
$>35$ & 45 & \\
Residence & 15 & 69.2 \\
Urban & 3 & 23.1 \\
Suburban & 2 & 4.6 \\
Rural & & 3.1 \\
Other & 61 & 93.8 \\
\hline Born again? & 4 & 6.2 \\
Yes & & \\
No & 55 & 84.6 \\
Has boy/girl friend? & 10 & 15.4 \\
Yes & & \\
No & 2 & 3.1 \\
\hline Eduactional level & 14 & 21.5 \\
Primary & 22 & 33.8 \\
Secondary & 26 & 40.0 \\
Tertiary college & & 1.5 \\
University & & 47.7 \\
Other & & \\
\hline Employment & & \\
Employed & & \\
Self-employed & & \\
Unemployed & 31 & \\
\hline & & \\
\hline
\end{tabular}

As shown in Table 1 above, majority of the participants $(60 \%)$ were aged 25 and below. In addition most of them were born again (93.8\%), in a boy/girlfriend relationship $(84.6 \%)$, urban $(69.2 \%)$, and in a form of employment $(52.3 \%)$. Further, majority had attained post-secondary education $(73.8 \%)$. In this study, male participants were slightly more than females.

Table 2. Whether participants expected their current relationships to lead to marriage

\begin{tabular}{|c|c|c|c|}
\hline \multirow{2}{*}{$\begin{array}{c}\text { Do you expect your relationship with } \\
\text { your boyfriend/ girlfriend to lead } \\
\text { into marriage? }\end{array}$} & \multicolumn{2}{|c|}{ Gender } & \multirow{2}{*}{ Total } \\
\cline { 2 - 3 } & Male & Female & \\
\hline $\begin{array}{c}\text { Yes : Frequency } \\
\% \text { within gender }\end{array}$ & 25 & 19 & 44 \\
\hline No: Frequency & $86.2 \%$ & $73.1 \%$ & $80.0 \%$ \\
$\%$ within gender & $13.8 \%$ & $26.9 \%$ & $20.0 \%$ \\
\hline $\begin{array}{c}\text { Total: Frequency } \\
\% \text { within gender }\end{array}$ & 29 & 26 & 55 \\
\hline
\end{tabular}

The 55 participants in a boy/girlfriend relationship were asked to indicate whether they expected that their current relationship would lead to marriage (see table 2 below).

As seen in table 2 above, majority of the participants $(80 \%)$ expected their current boy/girl relationship to lead to marriage. Interestingly, more males than females expected their current relationship to lead to marriage. More females were doubtful as to whether their current relationship would translate into marriage.

The participants were further asked to indicate the reasons why they would engage in marriage.

Table 3. Reasons why young people would engage in marriage in fut ure

\begin{tabular}{|c|c|c|c|}
\hline \multirow{2}{*}{$\begin{array}{l}\text { Why would you like to get married in } \\
\text { future? }\end{array}$} & \multicolumn{2}{|c|}{ Gender } & \multirow{2}{*}{ Total } \\
\hline & Male & Female & \\
\hline $\begin{array}{c}\text { Companionship : Frequency } \\
\% \text { within gender }\end{array}$ & $\begin{array}{c}20 \\
60.6 \%\end{array}$ & $\begin{array}{c}23 \\
71.9 \%\end{array}$ & $\begin{array}{c}43 \\
66.2 \%\end{array}$ \\
\hline $\begin{array}{c}\text { Bear children: Frequency } \\
\% \text { within gender }\end{array}$ & $\begin{array}{c}2 \\
6.1 \%\end{array}$ & $\begin{array}{c}5 \\
15.6 \%\end{array}$ & $\begin{array}{c}7 \\
10.8 \%\end{array}$ \\
\hline $\begin{array}{c}\text { Get a helper: Frequency } \\
\% \text { within gender }\end{array}$ & $\begin{array}{c}3 \\
9.1 \%\end{array}$ & $\begin{array}{c}1 \\
3.1 \%\end{array}$ & $\begin{array}{c}4 \\
6.2 \%\end{array}$ \\
\hline $\begin{array}{c}\text { Lonely: Frequency } \\
\% \text { within gender }\end{array}$ & $\stackrel{2}{6.1 \%}$ & $\begin{array}{c}1 \\
3.1 \%\end{array}$ & $\begin{array}{c}3 \\
4.6 \%\end{array}$ \\
\hline $\begin{array}{l}\text { Economic security: Frequency } \\
\% \text { within gender }\end{array}$ & $\begin{array}{c}1 \\
3.0 \% \\
\end{array}$ & $\begin{array}{c}2 \\
6.3 \%\end{array}$ & $\begin{array}{c}3 \\
4.6 \% \\
\end{array}$ \\
\hline $\begin{array}{l}\text { Family name: Frequency } \\
\% \text { within gender }\end{array}$ & $\begin{array}{c}5 \\
15.2 \%\end{array}$ & $\begin{array}{c}0 \\
0 \%\end{array}$ & $\begin{array}{c}5 \\
7.7 \%\end{array}$ \\
\hline $\begin{array}{c}\text { Total: Frequency } \\
\% \text { within gender }\end{array}$ & $\begin{array}{c}33 \\
100 \%\end{array}$ & $\begin{array}{c}32 \\
100 \%\end{array}$ & $\begin{array}{c}65 \\
100 \%\end{array}$ \\
\hline
\end{tabular}

As indicated in table 3 above, majority of the participants $(66.2 \%)$ gave companionship as the key reason they would engage in marriage. Other reasons why young people would enter into marriage included bearing children (10.8\%), preserving the family name $(7.7 \%)$, getting a helper $(6.2 \%)$, loneliness (4.6\%), and economic security (4.6\%). Notably, more males gave getting a helper, loneliness and preserving a family name as reasons why they would marry. On the other hand, mo re fe male participants cited companions hip, bearing children and economic security as reasons why they would marry. The participants were also asked to indicate the persons from whom they sought guidance regarding their relationships with boy/girlfriends (see table 4 below).

The participants were asked to state the persons from whom they sought guidance regarding their relationships. As shown in table 3 above, friends are the most popular source of relational guidance among the participants (49.2\%). Interestingly parents were the second most frequent source of relational guidance among the participants $(23.1 \%)$. Interestingly, $15.4 \%$ of the participants had their mothers as the source of intimate re lationship guidance while only $7.7 \%$ sought the same from their fathers. Gender differences in the pattern of seeking guidance from the parents were apparent in that more females sought guidance from mothers and more males sought the same from the father. Other important sources of relationship guidance among the young 
people were: Pastors $(10.8 \%)$; other relatives also formed $(9.2 \%)$ as well as couns ellors $(7.7 \%)$.

Table 4. Persons from whom relationship guidance is sought

\begin{tabular}{|c|c|c|c|}
\hline \multirow{2}{*}{$\begin{array}{l}\text { From whom would you seek } \\
\text { guidance about your relationship with } \\
\text { boy/girlfriend. }\end{array}$} & \multicolumn{2}{|c|}{ Gender } & \multirow{2}{*}{ Total } \\
\hline & Male & Female & \\
\hline Mother: $\quad$ Frequency & 4 & 6 & 10 \\
\hline$\%$ within gender & $12.1 \%$ & $18.8 \%$ & $15.4 \%$ \\
\hline $\begin{array}{c}\text { Father: Frequency } \\
\% \text { within gender }\end{array}$ & $\begin{array}{c}3 \\
9.1 \%\end{array}$ & $\begin{array}{c}2 \\
6.3 \% \\
\end{array}$ & $\begin{array}{c}5 \\
7.7 \% \\
\end{array}$ \\
\hline $\begin{array}{c}\text { Friends : } \quad \text { Frequency } \\
\% \text { within gender }\end{array}$ & $\begin{array}{c}19 \\
57.6 \%\end{array}$ & $\begin{array}{c}13 \\
40.6 \% \\
\end{array}$ & $\begin{array}{c}32 \\
49.2 \% \\
\end{array}$ \\
\hline $\begin{array}{c}\text { Other relative: Frequency } \\
\% \text { within gender }\end{array}$ & $\begin{array}{c}2 \\
6.1 \% \\
\end{array}$ & $\begin{array}{c}4 \\
12.5 \% \\
\end{array}$ & $\begin{array}{c}6 \\
9.2 \% \\
\end{array}$ \\
\hline $\begin{array}{c}\text { Pastor: Frequency } \\
\% \text { within gender }\end{array}$ & $\begin{array}{c}3 \\
9.1 \% \\
\end{array}$ & $\begin{array}{c}4 \\
12.5 \%\end{array}$ & $\begin{array}{c}7 \\
10.8 \% \\
\end{array}$ \\
\hline $\begin{array}{c}\text { Counsellor: Frequency } \\
\% \text { within gender }\end{array}$ & $\begin{array}{c}2 \\
6.1 \% \\
\end{array}$ & $\begin{array}{c}3 \\
9.4 \% \\
\end{array}$ & $\begin{array}{c}5 \\
7.7 \% \\
\end{array}$ \\
\hline $\begin{array}{c}\text { Total: } \\
\% \text { within gender } \\
\end{array}$ & $\begin{array}{c}33 \\
100 \% \\
\end{array}$ & $\begin{array}{c}32 \\
100 \% \\
\end{array}$ & $\begin{array}{c}65 \\
100 \% \\
\end{array}$ \\
\hline
\end{tabular}

The study also sought to find out the fears that the young urban Christians have about marriage. The results are as presented in table 5 below.

Table 5. Young people's fears about marriage

\begin{tabular}{|c|c|c|}
\hline Fear & Frequency $(\mathrm{N}=65)$ & Percentage (\%) \\
\hline Divorce & 12 & 18.5 \\
\hline Infidelity & 17 & 26.2 \\
\hline Loss of love & 5 & 7.7 \\
\hline Violence & 5 & 7.7 \\
\hline $\begin{array}{c}\text { Marrying the wrong } \\
\text { person }\end{array}$ & 7 & 10.8 \\
\hline Financial constraints & 4 & 6.2 \\
\hline Loss of freedom & 3 & 4.6 \\
\hline In-laws & 4 & 6.2 \\
\hline Loneliness & 3 & 4.6 \\
\hline Death of partner & 2 & 3.1 \\
\hline
\end{tabular}

Majority of the participants $(26.2 \%)$ feared marital infidelity and divorce $(18.5 \%)$. Others feared marrying the wrong person $(10.8 \%)$, loss of love in marriage $(7.7 \%)$ and violence $(7.7 \%)$. Financial constraints, marital loneliness, loss of freedom, in-laws and death of partner were also sources of fear about marriage among the young Christians.

\section{Discussion}

Our findings indicate that majority of young urban Christians in our sample are interested in marriage. Majority expect their current boy/girlfriend relationships to end in marriage. Although this expectation may be self-serving, it is consistent with findings in other areas that despite the changes in the timing of the first marriage, people still are interested in marriage[5, 7, 11,30].

That majority of the participants gave companionship and bearing children as the major reason they would wish to engage in marriage in future is consistent with evolutionary perspective to intimate relationships. In addition, consistent with the African traditions, many participants considered marriage as a way of preserving the family name. Notably, more female participants considered getting a companion, bearing children and economic security as reasons why they would marry while more male participants cited loneliness, getting a helper and preserving the family name as their reasons for future marriage. This is consistent with findings in earlier studies[26-31]. This may be due to gender roles socialization where men are perceived to be providers and home owners while women are viewed as caretaker for homes [5, 33-34]. The e mphas is on childbearing as reas on for marriage may be because in most Kenyan cultures, marriage, as a prelude to childbearing, is the most important determinant of adult status. Childbearing is viewed as a marker of role transition to adulthood [35].

In this study, friends were cited as the major sources of guidance in intimate relationships. This finding agrees with the assertion that the role and influence of friends for young adults is of major importance from the late teens to the mid-20s[36] and continues to be a source of support throughout adulthood[5]. The result further corroborates other findings where young people in Kenya have been found to rely on their friends on issues to do with their intimate relationships [32, 37-38]. In the light of these results, existing youth support services in churches should be strengthened in ways that translate young people's commitment and trust to one another into effective peer counselling. Close friends among young Christian should be charged to play a larger role in premarital guidance. The church could be used as an important arena in imparting peer counselling skills among young people.

Cultural factors strongly influence dating patterns and marriage preferences[38]. Most traditional cultures emphasize family ties and loyalty to parents [39]. The important role parents play in young adults' lives is underlined in the study finding that many of the respondents sought guidance about their relationships from their parents. Interestingly, mothers were the popular source of guidance for both boys and girls as compared to fathers. This could be a reflection of the changing family structure where mothers appear to be family leaders or an indication that mothers are more emotionally available for their children in the urban areas than fathers. While male participants outnumbered the females in depending on their friends and fathers for relationship guidance, female participants outnumbered them in seeking guidance fro $m$ their mothers, other relatives, pastors and counsellors. The findings are consistent with others that have found parents to be influential in young people's intimate relationships[40-41]. Other research among young people in Nairobi have found that although, they identified parents, then church leaders as their preferred and most trusted sources of information, very little guidance was coming from these sources[42]. The current study results imply that there are different community-based human resources to draw upon in church-based premarital counselling. It also implies that pastors should embrace referral of young people to other service and caregivers for guidance on interpersonal relationships. Since young people 
sought guidance from both couns ellors and pastors, churches could establish professional counselling departments as a way of helping young people grow spiritually, emotionally and socially. Such counselling departments would also tap from the advantages of doing specialized counselling in the context of one's local church.

The finding that women tend to have more sources about their guidance than men may indicate continuity in their socialized behaviours. Women base their friendships on emotional and intimate sharing and they tend to grow up discussing personal matters with friends. For men, confiding in others is inconsistent with the need to compete, and this may be the reason they are reluctant to seek guidance from different sources[41]. It is important to note that young wo men believe in seeking guidance from non-family sources. Current programming for adolescents and youth in sub-Saharan Africa is largely gender-blind and generic, and pays little attention to youth in differing circumstances, especially the most vulnerable[31]. Few programs are tailored to the special circumstances of young urban Christians encouraging them to seek relationship guidance from non-family sources. In addition, programming for young people often e mphasizes parent-child commun ication, overlooking the fact that many youth are not always with parents $[9,31]$. In addition, we tend to leave young people at the mercy of media and their peer networks for guidance regarding their marital relationships.

The finding that marital infidelity, divorce and marry ing the wrong person were the most feared issues about marriage implies that young people aspire for lasting, happy and sincere marital relationships. This underlies the value young people place on intimacy, which is an important ingredient for mature relationships [5]. Our finding corroborates other studies that have established that young people fear violence, divorce, and loss of love in their marital relationships [31, 42]. We suggest that young people who share the same fears about marriage could be brought together to encourage one another to develop confidence in the institution of marriage through church group-based interventions. Since our sample were committed Christians, we assume they already know their covenantal obligation to one another and this could be exploited to enhance premarital peer guidance.

\subsection{Limitations}

Several important limitations for the current study warrant mentioning.

The sample used in this study comprised mainly of young born again Christians from the Presbyterian Church of East Africa-Nairobi Presbytery. It is also important to note that all the young people from whom data was collected were members of church-based youth groups. The Presbyterian church youth groups have peer driven activities that focus on love relationships, responsible Christian life, and peer counseling. These groups are also expected to cultivate and nurture commitment to Christian values and Presbyterian doctrines among their members. We are persuaded that this group membership may have shaped the respondents' preferences and perceptions in ways quite different from what other young people may have given. Secondly, questions relating to one's fears and reasons for marriage may be subject to situational bias and social desirability bias owing to the religious beliefs one holds. Therefore, the data presented here may not represent the thought patterns of young Kenyans who are non staunch Christians or non-Christians. These peculiar sample characteristics may compromise the generalizability of their perceptions to young people from the wider Kenyan population.

There may also be methodological concerns about our administration of the questionnaires within group members. For example, it could be argued that group settings can perpetuate conformity and the repetition of similar ideas. Further, we did not do any statistical analys is to establish the significance of the reported gender differences. Therefore the reader should interpret the find ings with caution.

\section{Conclusions}

Since young Christians, especially female, seek guidance from different people, there is a need to diversify the sources of guidance regarding marital relationships for young people. We propose that church-based married and unmarried girls groups be encouraged in urban or semi-urban areas, since there is probably sufficient population density to favour their formation. Based on the findings we recommend that groups for married girls be used as a source of relationship guidance for young Christians to increase social networks. As with home-based activities, special care is needed to involve pastors and youth leaders during formation of such groups. The church based outreach or group mechanisms should also provide linkage to parental guidance, counseling services and peer counseling services. Given the barriers that the unmarried young people perceive about marriage, counselors and pastors should be available to offer marital guidance and refer the young urban Christians to other service providers.

\section{ACKNOWLEDGEMENTS}

We acknowledge all the young Christians from the Nairobi Presbytery who took part in this study. We further thank all the church leaders who assisted in mobilizing participants in this study.

\section{REFERENCES}

[1] Robert Havighurst, Developmental Tasks and Education, $3^{\text {rd }}$ ed. Textbook Publishers, 2003.

[2] Erik H. Erikson, The life cycle completed. Norton, USA, 1982.

[3] Montgomery, M.J., Psy chosocial intimacy and identity: From early adolescence to emerging adulthood, Journal of 
Adolescence Research, 20, 346-374, 2005.

[4] Dyke, P.H., Adams, G.R., Identity and Intimacy: An initial investigation of three theoretical models using cross-lag panel correlations, Journal of Youth and Adolescence, 19, 91-110, 1990.

[5] Robert V. Kail, John C. Cavan au gh, Human Development, A Life-span view, $5^{\text {th }}$ ed. Wadsworth, USA, 2010.

[6] Charlotte J. Patterson, Sexual Orientation Across the Lifespan: Introduction to the Special Section. Developmental Psychology, 44, 1 - 4, 2008.

[7] Maria Kefalas, Frank Furstenberg, Laura Napolitano, Marriage is More than Being Together: The Meaning of Marriage among Young Adults in the United States, Network on Transitions to Adulthood Research Network Working Paper, 2005.

[8] Fussell, Elizabeth, Frank Furstenberg, "Race, Nativity, and Gender Differences in the Transition to Adulthood in the 20th Century." In Richard Settersten, Frank Furstenberg, and Ruben Rumbaut (Eds.) On the Frontier of Adulthood: Theory, Research, and Public Policy. University of Chicago Press, USA, 2004.

[9] Kathryn Geldard, David Geldard, Relationship counselling for Children, Young People and Families, Sage, 2008.

[10] Wilson, James Q., The Marriage Problem: How Our Culture Has Weakened Families, Harper Collins, USA,2002.

[11] Bianca P. Acevedo, Arthur Aron, Does a Long-Term Relationship Kill Romantic Love? Review of General Psychology, Vol. 13, No. 1, 59-65 , American Psychological Association, 2009.

[12] Cherlin, Andrew, "The Deinstutionalization of Marriage." Journal of Marriage and the Family, 66 (4), 2004.

[13] Coontz, Stephanie, Marriage, a History: From Obedience to Intimacy, or How Love Conquered Marriage, Viking, USA, 2005.

[14] Goldstein, J.R. and C. T. Kenney. "Marriage Delayed or Forgone? New Cohort Forecasts of First Marriage for U.S. Women," American Sociological Review, 66, 505-519, 2001.

[15] Grote, N. K., Frieze, I. H. The measurement of friendship-based love in intimate relationships. Personal Relationships, 1, 275-300, 1994.

[16] Sternberg, R.J., A duplex theory of love. In R.J. Sternberg \& K. Weis (eds.), The new psychology of love (pp. 184-189), Yale University Press, USA, 2006.

[17] Monden, C., Partners in health? Exploring resemblance in health between partners in married and cohabiting couples, Social Psychology of Health \& Illness, 29, 391-411, 2007.

[18] Sher, T.G. Courtship and marriage: Choosing a primary relationship, in N. Vanzetti \& S. Duck (eds.) A lifetime of relationships (pp. 243-264). Brooks/Cole, USA, 1996.

[19] Sprecher Susan, Insiders' perspective on reasons for attraction to a close other, Social Psychology Quarterly, 61, 287-300, 1998.

[20] Agnew, Christopher R., Martz, John M., and Rusbult, Caryl. E., The Investment Model Scale: Measuring commitment level, satisfaction level, quality of alternatives, and investment size, Journal of Personal Relationships, 5: 357-391, 1998.

[21] Hatfield, E., \& Rapson, R. L., Historical and cross-cultural perspectives on passionate love and sexual desire. Annual Review of Sex Research, 4, 67-98, 1993.

[22] Fisher, H. E., Lust, attraction and attachment in mammalian reproduction. Human Nature, 9, 23-52. 1998.

[23] Fisher, H., The drive to love: The Neural mechanism for mate selection. In R.J. Sternberg \& K. Weis (Eds.), The new psy chology of love (pp. 87-115), Yale Unversity Press, USA, 2006.

[24] Keny a National Bureau of Statistics (KNBS) and ICF Macro. Kenya Demographic and Health Survey 2008-09. Calverton, Maryland: KNBS and ICF Macro, 2010.

[25] Worthman, C.M., Writing, J.W. Social change in adolescent sexual behavior, mate selection and premarital pregnancy rates in a Kikuyu community, Ethos, 15 (2), 146-165, 1987.

[26] Amina Abubakar, Preferred occupations in mate selection among undergraduate students from two Keny an universities: Implications for counseling, M.Ed thesis, Kenyatta University, Kenya, 2002.

[27] Sensibaugh, C.C., Mate selection preferences by heterosexual college students: a policy capturing approach, Ph.D. Thesis, Bowling Green State University, USA, 1997.

[28] Ramirez, S.A. Mate selection preferences among African Americans, MA thesis, Fayettevite State University, 1997.

[29] Buss, D. M., The evolution of love. In R. Sternberg \& K. Weis (Eds.), The new psychology of love (pp. 65-86) Yale University Press, USA, 2006.

[30] Marion M. Mory, Relationship satisfaction as a predictor of similarity ratings: a test of the attraction-similarity hypothesis, Journal of Social and Personal Relationships 22, (4) 561-584, 2005.

[31] Population council, Adolescence in Kibera Slums Nairobi, Population Concil, USA, 2007.

[32] Josephine W. Gitome, Integration of African indigenous guidance practices to adolescents' pastoral care and counselling programmes in selected churches of Nairobi, 2003, PhD thesis, Keny atta University, Keny a, 2003.

[33] Clark S., "Early marriage and HIV risks in sub-Saharan Africa" Studies in Family Planning, 35(3) 149-160, 2004.

[34] Menshc, B.S., Singh, S., Casterline,J.B., Trends in the timing of first marriage among men and women in the developing world, In Lloyd, C.B., Behrman, J.R., Stromquist, N.P., \& Cohen, B., (Eds.) the changing transitions to adulthood in developing countries: selected studies (pp.1180-171), National Reserch Council, USA, 2006.

[35] Arnett J.J. socialization in emerging adulthood: From the family to the wider world, from socialization to self-socialization, In J.E. Grusec \& P.D. Hastings (eds.) Handbook of socialization: Theory and research, pp. 208-231, Gulford press, USA, 2007.

[36] Kimani, G. W. K. Factors influencing adolescent precocity to sexual practice: A case study of secondary school students in 
Nairobi Province, Kenya. M.A. Thesis, Keny atta University, Kenya, 2005.

[37] Ndayala Phoebe Didi. Factors associated with Adolescent sexual behaviour of High school girls in Vihiga District. Msc Thesis, Keny atta University, Keny a, 2005.

[38] Parrot, A., Cummings,N., Forsaken females: the global brutalization of women, Rowman\& Littlefied, USA, 2006.

[39] Xiaohe, X., Whyte, M.K., Love matches and arranged marriages: A Chinese replication, Journal of Marriage and Family, 52, 709-722, 1990.
[40] Miller, B.C., Benson, B., Galbraith, K.A. Family relationships and adolescent pregnancy risk: A research synthesis, Developmental Review, 21, 1-38, 2001.

[41] Tenkorang, Eric, Maticka-Tyndale, E. Factors influencing the timing of first sexual intercourse among young people in Nyanza, Kenya. International Family Planning Perspectives, 34 (4): 177-188, 2008.

[42] Family Health International (FHI), Working with the church in Kenya to prevent the spread of HIV/AIDS, FHI360, Best Practices Case, 327-342, . 